\title{
A mortalidade em tempos de ventura e desventura: o Brás na virada do século XIX para o século XX*
}

\author{
Mortality in times of fortune and misfortune: Brás neighborhood at the turn \\ of the nineteenth century to the twentieth century
}

\section{Maria Silvia Bassanezi}

Universidade Estadual de Campinas

\section{Resumo}

Este estudo analisa a mortalidade - suas características e condicionantes - no distrito do Brás, um bairro tipicamente de imigrantes e operários da cidade de São Paulo, nos anos finais do século XIX e primeiros anos do século XX. A partir das estatísticas de óbitos produzidas e publicadas pela Repartição de Estatística e Arquivo do Estado de São Paulo, pode-se verificar que, naquele momento, a população desse bairro vivenciou um padrão de mortalidade característico de sociedade em pré-transição demográfica - alta mortalidade geral e alta mortalidade infantil - impactado pelo movimento imigratório, pelo ambiente, pelas condições de vida e trabalho e pela precariedade das políticas públicas de saúde.

Palavras-chave: Mortalidade; Imigração; Brás; São Paulo.

\begin{abstract}
This study analyzes the mortality - its characteristics and determinants - in the district of Brás, a typical immigrant and worker neighborhood in the city of São Paulo (Brazil), in the late nineteenth century and the early twentieth century. Based on the death statistics produced and published by the Bureau of Statistics and Archives of the State of São Paulo, this study shows that Brás experienced a mortality pattern characteristic of a society in demographic pre-transition - high overall mortality, mainly high child mortality - impacted by the immigration flow, the environment, the living and working conditions and the precariousness of public health policies.

Keywords: Mortality; Immigration; Brás; São Paulo.
\end{abstract}

\footnotetext{
*Uma versão preliminar deste texto foi apresentada no XI Congreso Asociación de Demografioa Histórica, em Cádiz (Espanha), realizado entre 21 e 24 de junho de 2016, como comunicação oral sob o título "A mortalidade entre as gentes pobres na terra hospedéira". Para este dossiê, o texto foi ampliado e revisto.
} 


\section{Dossiê
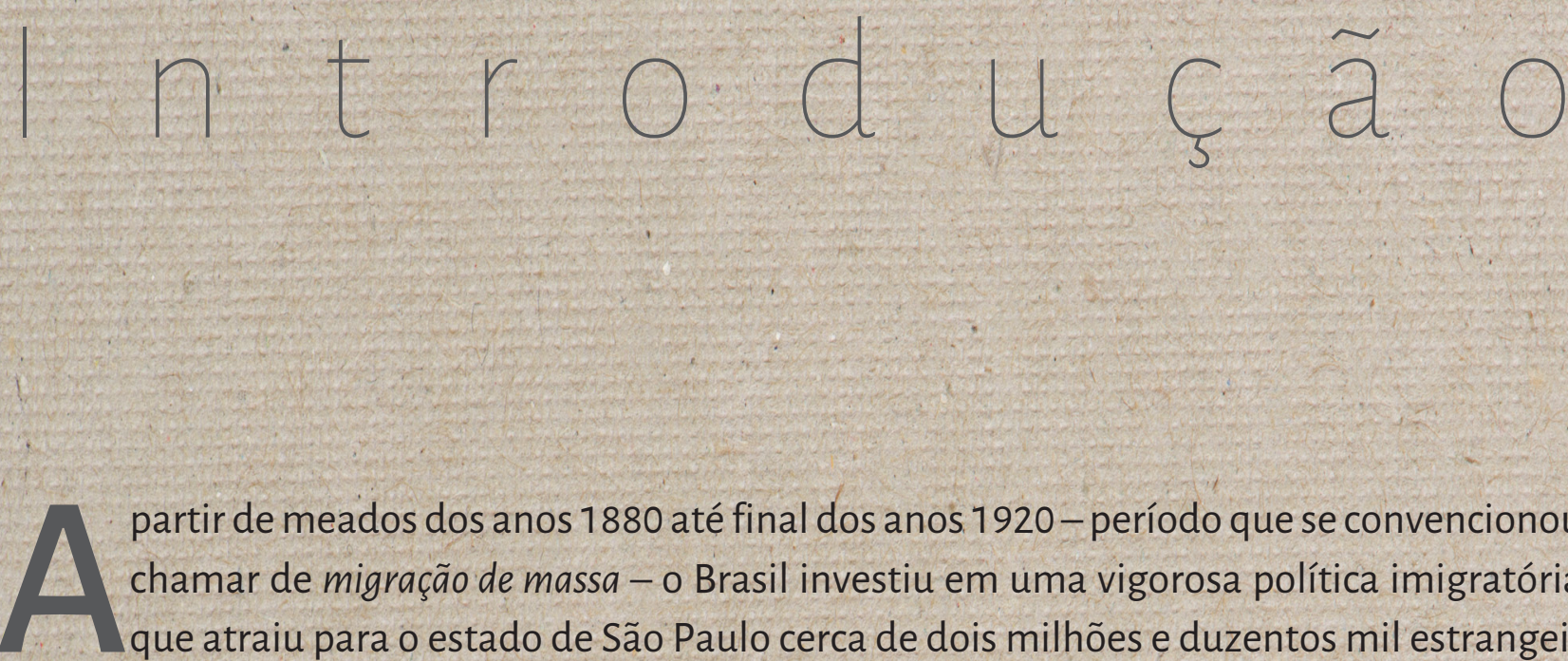

partir de meados dos anos 1880 até final dos anos 1920 - período que se convencionou chamar de migração de massa - o Brasil investiu em uma vigorosa política imigratória que atraiu para o estado de São Paulo cerca de dois milhões e duzentos mil estrangeiros, oriundos majoritariamente da Europa Mediterrânea'. Embora essa política privilegiasse a imigração familiar de europeus para o trabalho na lavoura do café, que se expandia a passos largos pelo interior paulista, muitos imigrantes se fixaram nas cidades, buscando outras oportunidades de vida e trabalho e contribuindo para intensificar o processo de urbanização, desenvolvimento econômico e crescimento populacional das mesmas.

Nesse contexto, a cidade de São Paulo, capital do estado de São Paulo, foi o grande polo de atração de uma parcela importante dos imigrantes subsidiados ${ }^{2}$ e espontâneos, que ocuparam os mais diversos espaços desta cidade. No seu conjunto, eram tanto imigrantes recém- chegados a São Paulo - vários deles chamados por familiares e conterrâneos já residentes em terras brasileiras - como imigrantes que se dirigiram primeiramente às fazendas de café ou aos núcleos urbanos do interior do estado e acabaram se estabelecendo na capital paulista.

A multidão tomou conta da cidade de São Paulo somente com a entrada em massa de imigrantes, fenômeno que se agravou ainda mais na segunda metade da década de noventa do século $\mathrm{XIX}$, quando os imigrantes abandonaram as fazendas de café e vieram para as áreas urbanas, principalmente para a capital. [...] A crise cafeeira e a redução da imigração subsidiada, proibida pelo Decreto Prinetti, redirecionaram o fluxo de trabalhádores para a Capital que se viu frente a uma crescente população, à criação de novos bairros e à instalação de fábricas e casas comerciais (RIBEIRO, 1991, p. 106).

Os levantamentos populacionais realizados no Brasil e no estado de São Paulo no período de migração de massa, e que trazem o volume dos estrangeiros ${ }^{3}$, dão uma ideia do ritmo e da

1 Cerca de um milhão e setenta mil imigrantes chegaram ao estado de São Paulo entre 1885 e 1904, dos quais 63,2\% eram italianos, $10,3 \%$ espanhóis, $8,9 \%$ portugueses e os demais eram imigrantes oriundos principalmente de outros países europeus (LEVY, 1974).

2 Entre 1890 e 1902, os imigrantes subsidiados no estado de São Paulo lideravam com $78 \%$ das entradas.

3 Os levantamentos de população arrolam os estrangeiros residentes no Brasil no momento de sua realização, sem distinguir o imigrante do não imigrante. No entanto, a história mostra que a população estrangeira, na sua quase totalidade, confunde-se com a população imigrante na época. 
dimensão do fenômeno imigratório na cidade de São Paulo, de seus efeitos diretos e indiretos sobre o volume e sobre a dinâmica populacional local. Em 1886, a população da cidade era de 47.697 habitantes; quatro anos depois (1890), esta já somava 64.934 moradores, dos quais pouco mais de um quarto eram estrangeiros (25,8\%). Logo em seguida (1893), os estrangeiros na cidade passaram a responder por mais da metade da população local $(54,6 \%)$ - proporção que, provavelmente, foi maior nos anos finais do século XIX4, uma vez que o movimento imigratório foi mais intenso na década de 1890, com um máximo de entradas em 1895, elevando a população da cidade para cerca de 240 mil habitantes em 1900. Em 1920 e, depois, em 1934, quando a entrada de imigrantes internacionais havia enfraquecido e os filhos brasileiros de imigrantes ampliavam o segmento brasileiro $0^{5}$, as pessoas nascidas no exterior ainda tinham um peso importante na população da cidade ( 205.245 pessoas em 1920 e 287.690 em 1934 , respectivamente $35,4 \%$ e $27,8 \%$ da população total).

Entre os diversos espaços ocupados pelos imigrantes na cidade de São Paulo encontrava-se o bairro ou distrito do Brás, espaço privilegiado por este trabalho. Conhecido como um bairro tipicamente de imigrantes e de operários, o Brás vivenciou intensamente a mortalidade das "venturas e desventuras" na virada do século XIX para o século XX, como mostram as estatísticas de óbitos ali ocorridos entre 1895 e 1904.

Essas estatísticas foram produzidas e publicadas pela Repartição de Estatística e Arquivo do Estado de São Paulo em Relatórios e Anuários, que sistematizam também as informações sobre nascimentos e casamentos do registro civil e tinham como objetivo subsidiar as políticas públicas, entre elas as de imigração e saúde. Essas estatísticas, no entanto, devem ser vistas com certa cautela, pois apresentam algumas lacunas, erros de agregação e embutem sub-registro dos eventos vitais. Também não seguem a mesma forma de apresentação no decorrer do tempo e nem sempre dispõem de cruzamentos de informações que seriam importantes à análise da dinâmica demográfica. Contudo, se elas não podem dar conta de toda a realidade, elas trazem pistas e assinalam tendências que permitem saber um pouco mais sobre a dinâmica demográfica, na virada do século XIX para o século XX, período que sofre, inclusive, a carência de $\operatorname{censos}^{6} \mathrm{e}$, no caso específico deste trabalho, da mortalidade entre gentes imigrantes e pobres do Brás.

4 As informações publicadas do recenseamento de 1900 não trazem a população segundo a nacionalidade. Contudo, as estatísticas de entrada de imigrantes mostram que, na década de 1890, chegaram ao estado de São Paulo 734.985 imigrantes (LEVY, 1974).

5 Os filhos de estrangeiros nascidos no Brasil èram considerados brasileiros segundo normas da época, a não ser que se declarassem em contrário, o que raramente acontecia.

6 Para o período de imigração de massa, somente os censos nacionais de 1890 e 1920 , o levantamento populacional da Província de São Paulo de 1886 e o Recenseamento do Município da Capital, em 30 de setembro de 1893, dispõem de algumas informações sobre a população do Brás. 
A partir principalmente dessas fontes, mas também dos relatórios da Secretaria dos Negócios da Agricultura, Comércio e Obras Públicas - que trazem estatísticas dos imigrantes encaminhados para a enfermaria da Hospedaria de Imigrantes e dos óbitos ali ocorridos - e de outras de caráter quantitativo e qualitativo, este trabalho busca verificar o impacto do movimento imigratório, das condições de vida, do ambiente e das políticas públicas de saúde sobre a mortalidade vivenciada no bairro do Brás naquela virada de século.

\section{O Brás imigrante e operário}

Situado na região centro-leste da cidade de São Paulo, o Brás - cuja origem remonta à segunda metade do século XVIII-somente nas últimas décadas do século XIX começou a passar por um processo de urbanização e crescimento populacional intenso. Nessa época, foram instaladas em seu território: estações ferroviárias, ligando o bairro diretamente ao porto de Santos, ao Rio de Janeiro e ao interior do estado; Hospedaria de Imigrantes, construída para abrigar os imigrantes recém-chegados - dos quais muitos acabaram por se fixar nesse bairro; oficinas e fábricas, graças ao baixo custo de terrenos e à oferta de mão de obra; além de um pequeno comércio para atender a população local em crescimento (RIBEIRO, 1991).

Em 1886, a população do Brás somava 5.998 pessoas ( $9,6 \%$ da população da capital); sete anos depois (1893), já contabiliza 32.387 indivíduos (25\% da população da capital), dos quais $62,6 \%$ eram estrangeiros. Do conjunto de estrangeiros, a imensa maioria era oriunda da Itália $(60,7 \%)$, uma parcela razoável de Portugal $(24,4 \%)$, outra da Espanha $(11,3 \%)$ e o restante de países diversos.

Para a virada do século XIX para o século XX, não se tem informações confiáveis sobre a população local. Contudo, pode-se deduzir que, nesse momento, ela era bem maior e que os italianos predominavam em muito a comunidade imigrante, dando ao Brás uma feição de bairro italiano por excelência. De fato, nos anos 1890, o movimento migratório em direção ao Brasil esteve em seu auge e os italianos representavam a maior. parcela das entradas de imigrantes. 0 recenseamento de 1920 traz para o distrito do Brás uma população de 67.074 habitantes, dos quais ainda $43 \%$ eram estrangeiros. A queda no ritmo de crescimento populacional do Brás no período deveu-se, sobretudo, a perdas territoriais em função da criação de novos distritos na capital paulista. O declínio da proporção de imigrantes estrangeiros na população ocorreu 
em virtude dos efeitos indiretos da imigração, ou seja, dos muitos filhos que os imigrantes geraram no local, considerados brasileiros - no conjunto dos anos aqui analisados, $87,6 \%$ das crianças nascidas no Brás eram filhas de pai estrangeiro e $85,8 \%$ delas nascidas de mãe estrangeira. O perfil da população imigrante favorecia os níveis de natalidade, pois, em sua maioria, os imigrantes se encontravam em idade produtiva e reprodutiva. Eles somavam mais homens que mulheres e uma parcela bastante significativa deles fázia parte de unidades familiares.

Os imigrantes, desprovidos de recursos financeiros e majoritariamente pobres - no Brás e em outros espaços da capital paulista -, além de enfrentarem condições ambientais e culturais distintas da terra natal, eram obrigados a viver em condições muito precárias em termos de moradia e trabalho, sem higiene, sem saneamento básico, sem assistência à saúde, sem uma alimentação saudável.

Os aluguéis das casas eram caros e consumiam boa parte da renda familiar. Para muitos era impensável viver em casas que não fossem os cortiços. Como descreve Trento (1989, p. 138):

Os cômodos úmidos, enlameados, sujos, com paredes e tetos pretos de fumaça, que abrigavam famílias inteiras [...]. Faltava ar, luz, espaço, esgoto e higiene. O quintal em comum, às vezes, transformava-se num charco, mais frequentemente num depósito de lixo, onde as crianças passavam o dia brincando e as mulheres lavando roupa, junto a uma única latrina quase sempre em estado lastimável.

O local de trabalho não diferia em termos de salubridade. As ruas, por sua vez, não eram calçadas, estavam sempre cobertas de lama. O lixo se acumulava e gerava mau cheiro, proliferando os insetos e ratos. O abastecimento de água era insuficiente e a rede de esgoto precária.

Tal contexto favorecia a ocorrência e proliferação de epidemias e de outras doenças - desconhecidas do sistema imunológico dos imigrantes e/ou trazidas pelos próprios da Europa.

A precariedade com que viviam os trabalhadores imigrantes pobres e seus descendentes foi objeto de muitas denúncias na imprensa, que criticava com frequência a administração da capital pelo descaso e abandono com que tratava os bairros distantes do centro da cidade e onde eles se aglomeravam. As autoridades, por sua vez, reconheciam os problemas de saúde pública nesses locais, como atestam muitos dos relatórios que produziram na época. Promulgaram leis, criaram uma série de órgãos ${ }^{7}$, como o Serviço Sanitário, por exemplo, mas medidas efetivas para combater a morbimortalidade foram ineficientes ou inexistentes por muitos anos (RIBEIRO, 1991; TELAROLLI ]R, 1996).

$\overline{7 \text { Ver Ribeiro (1991) }}$ 
A alimentação também não merecia maiores cuidados. As crianças eram as mais prejudicadas: a elas eram servidos alimentos impróprios e nocivos à sua idade. Mães, inclusive, eram levadas "a alimentar artificialmente seus filhos afim de mediante retribuição pecuniária, amamentar os [filhos] dos mais abastados" (REPARTIÇÃO, 1903, p.118).

\section{A mortalidade entre as gentes do Brás}

Na virada do século XIX para o séculoXX, a população da cidade de São Paulo se encontrava em uma fase pré-transição demográfica: os níveis de mortalidade geral, de mortalidade infantil e de natalidade eram altos, e traziam embutidos os reflexos da entrada massiva de imigrantes ${ }^{8}$. As epidemias assolavam a cidade, provocando muitas mortes juntamente com as doenças do aparelho digestivo, do aparelho respiratório e a tuberculose. As variações bruscas de temperatura que ocorriam na cidade contribuíam para ampliar os casos de mortalidade por doenças respiratórias. Por outro lado, as condições climáticas impediam que a febre amarela provocasse muitos óbitos, ao contrário do que ocorria na cidade portuária de Santos, no município de Campinas e em outras das regiões cafeeiras do estado de São Paulo, onde epidemias de febre amarela dizimaram uma parcela razoável da população (BASSANEZI, 2014; MORAES, 2014).

Se a situação da cidade de São Paulo era tal, a do Brás, seu bairro mais populoso e onde se encontrava a Hospedaria de Imigrantes, era pior. Enfermidades e mortes rondavam imigrantes recém-chegados alojados nessa hospedaria, onde tinham o direito a permanecer por até oito dias. Fragilizados por uma longa e extenuante viagem, muitos chegavam ali enfermos ou ali contraiam alguma doença. Eles eram atendidos e triados na enfermaria, que encaminhava aqueles com doenças contagiosas (crupe, febre tifoide, febre amarela, varíola) para o Hospital de Isolamento; os portadores de moléstias crônicas ou de tratamento demorado (tuberculose, enfermidade do aparelho circulatório) iam para a Santa Casa de Misericórdia; enquanto as parturientes com risco de vida, eram encaminhadas para Maternidade, e os que apresentavam quadro de demência, para o Hospital dos Alienados (SECRETARIA DOS NECÓCIOS, 18981904).

No conjunto dos anos de 1898 a 1904 - para os quais se tem informações mais completas dentre os 10 anos privilegiados para a análise - dos 2.370 pacientes atendidos na enfermaria da

8 Durante a década de 1890 , a taxa, bruta de natalidade alcançou a cifra de $40 \%$, compensando a também alta taxa bruta de mortalidade de $28 \%$ (BASSANEZI, 2014). 


\section{História Econômicag $\quad$ Dossiê
Demografia Históncá}

hospedaria, $69,5 \%$ receberam alta, $17,2 \%$ foram encaminhados para hospitais e $10,9 \%$ faleceram ali mesmo. Os que foram a óbito eram predominantemente crianças (cerca de $90 \%$ ) que não tiveram a mínima chance de experimentar o viver na terra hospedeira. Faleciam vítimas de moléstias do aparelho digestivo (principalmente enterite e enterocolite), de moléstias do aparelho respiratório (pneumonia, broncopneumonia, bronquite), de sarampão (Tabelas 1, 2 e 3).

Tabela 1 - Imigrantes atendidos na enfermaria da Hospedaria de Imigrantes (São Paulo-1898-1904)․․

\begin{tabular}{|c|c|c|c|c|c|}
\hline Ano & Entrados na enfermaria & Receberam alta & $\begin{array}{c}\text { Encaminhados para } \\
\text { hospitais }\end{array}$ & $\begin{array}{c}\text { Faleceram na enfermaria } \\
\text { Permaneceram em } \\
\text { tratamento }\end{array}$ \\
\hline 1898 & 162 & 124 & 10 & 26 & 2 \\
\hline 1899 & 355 & 288 & 23 & 37 & 7 \\
\hline 1900 & 115 & 69 & 17 & 98 & 1 \\
\hline 1901 & 848 & 624 & 83 & 54 & 47 \\
\hline 1902 & 566 & 451 & 61 & 43 & \\
\hline 1903 & 92 & 5 & 130 & 16 & 259 \\
\hline 1904 & 232 & 86 & 407 & 57 \\
\hline
\end{tabular}

Fonte: Secretaria dos Negócios da Agricultura, Commercio e Obras Públicas. Relatórios 1898-1904.

Tabela 2 -Óbitos ocorridos na enfermaria da Hospedaria de Imigrantes por grupo etário. (São Paulo-1898-1904) ${ }^{10}$.

\begin{tabular}{|c|c|c|c|c|}
\hline Ano & Menores de 12 anos & Maiores de 12 anos & Total & \%de óbitos de menores de 12 anos de idade \\
\hline 1898 & 23 & 3 & 26 & 88,5 \\
\hline 1900 & 26 & 2 & 28 & 92,9 \\
\hline 1907 & 90 & 4 & 94 & 95,7 \\
\hline 1902 & 51 & 3 & 54 & 94,4 \\
\hline 1903 & 2 & 2 & 4 & 50,0 \\
\hline 1904 & 15 & 1 & 76 & 93,8 \\
\hline Total & 193 & 29 & 222 & 86,9 \\
\hline
\end{tabular}

Fonte: Secretaria dos Negócios da Agricultura, Commercio e Obras Públicas. Relatórios 1898-1904.

Tabela 3 -Óbitos ocorridos na enfermaria da Hospedaria de Imigrantes por causa morte. (São Páulo-1898-1904) ${ }^{11}$.

\begin{tabular}{|c|c|}
\hline Causa de morte & \% de óbitos \\
\hline Moléstias do aparelho digestivo & 24,0 \\
\hline Moléstias do aparelho respiratório & 16,3 \\
\hline Sarampão & 12,9 \\
\hline Mal definida ("morte súbita") & 13,7 \\
\hline Outras möléstias & 33,1 \\
\hline Total & 100,0 \\
\hline
\end{tabular}

Fonte: Secrètaria dos Negócios da Agricultura, Commercio e Obras Públicas. Relatórios 1898-1904.

9 No ano de 1901 houve um aumento sensível de entrada de imigrantes devido à piora das condições dos camponeses na Itália, à restrição à imigração na República Argentina e ao aumento da imigração espontânea (SECRETARIA DOS NECÓCIOS, 1901). A queda do movimento imigratório, no ano de 1903, reflete a proibição da imigração subsidiada ao Brasil por parte da Itália em 1902. 10 Não há informação por grupo etário para o ano de 1899.

11 Não há informação por causa de morte para o ano de 1898. 
Se a busca por uma vida melhor foi interrompida para uma parcela dos imigrantes nos primeiros dias de Brasil, muitos daqueles que se estabeleceram no Brás e seus filhos brasileiros não tiveram melhor sorte: 12.762 deles foram vítimas de enfermidades que os levaram a óbito, entre 1895 e 1904.

A ausência de informações censitárias impede a elaboração de cálculos das taxas brutas de mortalidade. Contudo, as taxas de mortalidade infantil ${ }^{12}$ passíveis de serem calculadas com as informações disponíveis, assim como o cálculo das proporções de óbitos por idade, deixam entrever a situação calamitosa da mortalidade no Brás, na virada do século XIX para o século XX.

A taxa média de mortalidade infantil no Brás entre 1896 e $1904^{13}$ alcançou a cifra de $246,6 \%$, maior que na cidade de São Paulo como um todo $(226,6 \%$ ) e nas regiões cafeeiras que receberam um volume grande de imigrantes e que sofreram com surtos de febre amarela, como é o caso de Campinas e de Ribeirão Preto: 193,7\%o e 185,4\%o em média, respectivamente (Tabela 4). Nesses municípios, as taxas de mortalidade infantil, embora altas, eram menores que as do Brás e da capital como um todo, muito provavelmente porque a alimentação nesses locais era melhor que na capital ${ }^{14} \mathrm{e}$, embora as moradias fossem muitas vezes precárias e o trabalho árduo, a aglomeração de pessoas era bem menor nas fazendas de café e nos núcleos urbanos do interior. A mortalidade infantil no Brás superou, inclusive, a média da vivenciada pelo continente europeu em meados do século XVIII (200\%o), como apontada por Livi-Bacci (1999).

No ano de 1898, quando a cidade de São Paulo foi atingida por uma epidemia de varíola, a taxa de mortalidade infantil subiu para $260,4 \%$ e a do Brás atingiu $280,3 \%$ o. Os casos de varíola no Brás, nesse ano, corresponderam a $13,6 \%$ dos óbitos da capital e destes $60 \%$ ceifaram a vida de crianças entre 0 e 5 anos de idade ${ }^{15}$.

Tabela 4-Taxas de mortalidade infantil (1896-1904).

\begin{tabular}{|c|c|c|c|c|}
\hline Ano & Brás & Cidade de São Paulo & Campinas & Ribeirão Preto \\
\hline 1896 & 266,4 & 250,5 & 297,7 & 224,2 \\
\hline 1897 & 243,8 & 231,1 & 224,8 & 182,7 \\
\hline 1898 & 280,3 & 260,4 & 203,3 & 172,6 \\
\hline 1899 & 200,1 & 162,7 & 183,6 & 166,2 \\
\hline 1900 & 213,4 & 206,9 & 182,2 & 189,0 \\
\hline 1901 & 273,9 & 234,4 & 188,1 & 197,2 \\
\hline 1902 & 246,2 & 238,2 & 177,1 & 221,0 \\
\hline 1903 & 249,6 & 220,4 & 141,3 & 164,1 \\
\hline 1904 & 245,6 & 229,8 & 145,6 & 151,3 \\
\hline
\end{tabular}

Fonte: Repartição de Estatistica e do Archivo do Estado de São Paulo (1896-1907).

12 Número de óbitos de menores de um ano de idade por mil nascidos vivos, em determinado espaço geográfico e determinado período de tempo.

13 Para 1895, faltam informações necessárias para o devido cálculo.

14 Nas fazendas cafeeiras, a família imigrante podia contar com uma parcela de terra para o cultivo de milho, feijão e arroz, uma pequena horta e criação de animais de pequeno porte para sua subsistência.

15 Os grupos etários neste trabalho seguem a forma com que aparecem no documento original. 
Se muitíssimas crianças não sobreviveram ao primeiro ano de vida, outras não chegaram a completar mais que cinco anos de idade. As estatísticas mostram que crianças de 0 a 5 anos de idade responderam por $75 \%$ dos óbitos ocorridos no Brás no período (Tabela 5) - uma proporção muito maior do que a observada para o conjunto da cidade de São Paulo para as décadas de 1890 e de 1900 (55\%) e para Campinas, entre 1890 e 1900 (47\%), época em que este município passou por vários surtos de febre amarela que dizimaram muitas vidas infantis entre $0 \mathrm{e}$ 4 anos de idade (BASSANEZI, 2014; MORAES, 2014).

Tabela 5-Mortalidade por grupo de idade.

\begin{tabular}{|c|c|c|c|c|c|c|c|c|c|c|c|}
\hline Idade & 1895 & 1896 & 1897 & 1898 & 1899 & 1900 & 1901 & 1902 & 1903 & 1904 & Total \\
\hline 0 a 5 & 81,9 & $-75,1$ & 76,5 & 75,9 & 74,1 & 72,9 & 78,1 & 72,6 & 72,5 & 74,0 & 75,6 \\
\hline 6 a 10 & 2,2 & 3,6 & 3,2 & 2,1 & 2,9 & 1,9 & 3,1 & 2,5 & 0,7 & 1,8 & 2,5 \\
\hline 11 a 15 & 0,9 & 1,4 & 0,8 & 0,7 & 0,8 & 1,1 & 1,3 & 0,7 & 1,0 & 1,0 & 1,0 \\
\hline 16 a 20 & 1,6 & 1,5 & 2,3 & 1,0 & 1,1 & 1,9 & 1,0 & 0,9 & 1,2 & 2,3 & 1,5 \\
\hline 21 a 30 & 2,8 & 4,4 & 3,9 & 4,9 & 4,2 & 4,5 & 2,9 & 4,2 & 5,0 & 3,7 & 4,0 \\
\hline 31 a 40 & 3,1 & 3,8 & 4,7 & 5,0 & 4,3 & 3,9 & 3,9 & 4,7 & 5,7 & 4,7 & 4,3 \\
\hline 47 a 50 & 2,8 & 3,3 & 3,1 & 3,5 & 4,7 & 4,6 & 3,7 & 3,8 & 3,3 & 3,7 & 3,4 \\
\hline 51 a 60 & 1,8 & 2,3 & 2,3 & 3,0 & 3,7 & 4,7 & 2,8 & 3,4 & 4,6 & 3,5 & 3,1 \\
\hline 61 a 70 & 1,6 & 2,1 & $\begin{array}{l}7,1 \\
\end{array}$ & 1,8 & 1,8 & 2,9 & 1,6 & 2,6 & 2,7 & 2,3 & 2,0 \\
\hline 71 a 80 & 0,6 & 1,0 & 1,0 & 1,4 & 1,1 & 1,1 & 1,4 & 1,8 & 1,7 & 1,4 & 1,2 \\
\hline 80 a 100 & 0,3 & 0,5 & 0,0 & 0,4 & 0,8 & 0,6 & 0,3 & 0,8 & 0,7 & 1,3 & 0,5 \\
\hline$>100$ & 0,0 & 0,1 & 0,0 & 0,0 & 0,0 & 0,0 & 0,0 & 0,0 & 0,0 & 0,0 & 0,0 \\
\hline ignorado & 0,5 & 0,9 & 1,0 & 0,3 & 1,1 & 0,0 & 0,0 & 2,0 & 0,9 & 1,1 & 0,8 \\
\hline Total & 100,0 & 100,0 & 100,0 & 100,0 & 100,0 & 100,0 & 100,0 & 100,0 & 100,0 & 100,0 & 100,0 \\
\hline
\end{tabular}

Fonte: Repartição de Estatistica e do Archivo do Estado de São Paulo (1896-1907).

No ano de 1895, o de maior entrada de imigrantes no estado de São Paulo, os óbitos de crianças dessa faixa etária no Brás chegaram a mais de $80 \%$ no conjunto de óbitos registrados (Tabela 4). Se à boca pequena o povo dizia que "S. Paulo não é uma cidade para creanças e nem velhos" (DIRECTORIA DO SERVIÇO SANITARIO, 1905, p. 25), o Brás muito menos ainda.

Essas crianças eram vítimas, principalmente, de moléstias do aparelho digestivo (gastroenterites, enterites e enterocolite), responsáveis por cerca de $1 / 3$ dos óbitos, causados normalmente por ingestão de alimentos e água contaminados, característicos das épocas quentes, e por vários outros alimentos inadequados servidos às crianças (Tabela 6). Em ordem decrescente de grandeza vinham, em seguida, as moléstias do aparelho respiratório (bronquites, broncopneumonia e pneumonia), próprias de épocas de clima mais frio, que junto às anteriores ceifaram a vida de mais da metade das crianças nessas idades. 
Tabela 6-Causa de morte de 0 a 5 anos de idade. Brás 1895-1904.

\begin{tabular}{|l|r|}
\hline Causa de morte & $\%$ \\
\hline Moléstias especiais dos recém-nascidos & 7,9 \\
\hline Mortes violentas & 0,9 \\
\hline Moléstias infecciosas e epidêmicas & 8,7 \\
\hline Moléstias generalizadas & 1,8 \\
\hline Moléstias do sistema nervoso & 8,9 \\
\hline Moléstias do aparelho circulatório & 1,0 \\
\hline Moléstias do aparelho respiratório & 23,2 \\
\hline Moléstias do aparelho digestivo e anexos & 34,5 \\
\hline Moléstias do aparelho genito-urinário & 0,6 \\
\hline Moléstias da pele e do tecido celular & 0,3 \\
\hline Moléstias mal determinadas & 11,8 \\
\hline Sem declaração de moléstia & 1,1 \\
\hline Total & 100,0 \\
\hline
\end{tabular}

Fonte: Repartição de Estatistica e do Archivo do Estado de São Paulo (1896-1907).

Em menor escala, as crianças morriam das doenças do sistema nervoso (meningite e convulsões) e das moléstias infecciosas (febre tifoide e sarampão). Doenças especiais dos recém-nascidos igualmente tiravam a vida de bebês em poucos minutos, horas ou dias após seu nascimento. No seu conjunto, poucas crianças foram a óbito por morte violenta, mas vale chamar a atenção para o dado de que essas mortes eram provocadas por queimaduras, demonstrando que a ausência de cuidados às crianças não se restringia apenas à má alimentação (Tabela 6).

Paralelamente ao número elevado de crianças que perdiam a vida, soma-se um volume alto de seres gerados, que não chegaram a ver a luz do dia, pois nasceram mortos (1.200 no período analisado).

Separando os óbitos de crianças de 0 a 5 anos por nacionalidade, e extraídos o número dos falecidos por "moléstias especiais dos recém-nascidos", observam-se algumas poucas diferenças na proporção das causas de morte entre as crianças nascidas no Brasil e as nascidas no exterior. Os números indicam que os estrangeiros apresentavam porcentagens de óbito um pouco mais elevadas que os brasileiros quanto às moléstias infecciosas e epidêmicas, as generalizadas, e as do aparelho respiratório e digestivo, e e porcentagens menores nas demais causas, principalmente no que tange às moléstias do sistema nervoso, predominantemente as convulsões e meningites (Tabela 7).

As crianças imigrantes, além de enfrentarem uma longa e penosa viagem que as debilitavam, confrontavam em terras paulistanas condições ambientais distintas da terra natal. Fragilizadas, elas sentiam a mudança de clima, a falta de resistência a determinadas doenças, as duras 
condições de vida encontradas no bairro, o que aumentava as chances de irem a óbito. Tal fato, porém, não significa que as nascidas no Brasil também estivessem isentas de falecerem em proporções altas das mesmas moléstias que mais ceifavam as estrangeiras (Tabela 7).

Tabela 7 - Óbitos de crianças de 0 a 5 anos de idade segundo a nacionalidade. Brás 1895-1904.

\begin{tabular}{|l|c|c|}
\hline Causa de morte & Brasileira (\%) & Estrangeira (\%) \\
\hline Mortes violentas & 1,1 & 0,8 \\
\hline Moléstias infecciosas e epidêmicas & 8,3 & 9,4 \\
\hline Moléstias generalizadas e diásteses & 1,0 & 2,8 \\
\hline Moléstias do sistema nervoso e órgãos da sensibilidade & 11,1 & 8,1 \\
\hline Moléstias do aparelho circulatório & 0,7 & 1,5 \\
\hline Moléstias do aparelho respiratório & 24,9 & 25,5 \\
\hline Moléstias do aparelho digestivo eanexos & 36,8 & 38,1 \\
\hline Moléstias do aparelho genito-urinário & 0,9 & 0,4 \\
\hline Moléstias da pele e do tecido celular & 0,4 & 0,3 \\
\hline Moléstias dos órgãos da locomoção & 0,0 & 0,0 \\
\hline Moléstias mal determinadas & 13,2 & 12,3 \\
\hline Sem declaração de moléstia & 1,5 & 0,8 \\
\hline Total & 100,0 & 100,0 \\
\hline
\end{tabular}

Fonte: Repartição de Estatistica e do Archivo do Estado de São Paulo (1896-1907).

A alta mortalidade de crianças no Brás era justificada "pela densidade de sua população, em geral constituída de gente pobre, mal alojada, mal alimentada, pouco instruída e refratária a preceitos de higiene", e pela ignorância das mães quanto aos princípios de profilaxia (DIRECTORIA DO SERVIÇOSANITARIO, 1903, p. 112-113).

Os anos foram passando e essa situação parece não ter se modificado, pois na terceira década do século $X X$ as autoridades sanitárias ainda continuavam apontando como base para os altos índices de mortalidade infantil a má alimentação das crianças, o trabalho da mãe fora do lar, a insalubridade da habitação, a gestação mal conduzida, doenças hereditárias, incompetência das parteiras, ignorando a falta de participação do poder público: “Esses óbitos são devidos, sem dúvida, em grande parte, á incúria das mães e á falta absoluta das rudimentares noções de hygiene-infantil, noções estas, que necessitam ser administradas á população baixa onde esses falecimentos se contam em maior número" (SERVIÇO SANITÁRIO, 1924, p. 98).

De modo geral, em todas as faixas etárias morriam mais homens que mulheres ( $55 \%$ em média), porque eles eram maioria na população local e porque os homens jovens e adultos "em idade produtiva era o grupo de maior mobilidade dentro da população em decorrência de suas atribuições no processo de trabalho e na organização familiar" (TELAROLLI JR., 2003, p. 30), ou seja, 
eles circulavam pelos locais mais movimentados e, portanto, estavam mais expostos às doenças transmissíveis que levavam ao óbito. As mulheres, por sua vez, além de enfrentarem as mesmas enfermidades que atacavam os homens em grandes proporções, eram ainda vítimas das moléstias que conduziam à mortalidade materna, principalmente aquelas entre 15 e 30 anos.

Tabela 8-Causa de morte de maiores de 5 anos idade. Brás $1895-1904^{16}$.

\begin{tabular}{|l|c|}
\hline Causa de morte & $\%$ \\
\hline Marasmo senil & 2,4 \\
\hline Mortes violentas & 2,8 \\
\hline Moléstias infecciosas e epidêmicas & 20,9 \\
\hline Moléstias generalizadas & 4,7 \\
\hline Moléstias do sistema nervoso & 8,3 \\
\hline Moléstias do aparelho circulatório & 18,6 \\
\hline Moléstias do aparelho respiratório & 74,5 \\
\hline Moléstias do aparelho digestivo e anexos & 14,2 \\
\hline Moléstias do aparelho genito-urinário & 3,4 \\
\hline Moléstias da pele e do tecido celular & 0,9 \\
\hline Moléstias dos órgãos da locomoção & 0,4 \\
\hline Moléstias mal determinadas & 5,3 \\
\hline Sem declaração de moléstia & 3,7 \\
\hline Total & 100,0 \\
\hline
\end{tabular}

Fonte: Repartição de Estatistica e do Archivo do Estado de São Paulo (1896-1907).

Entre os óbitos de pessoas maiores de cinco anos (Tabela 8), predominavam os provocados por moléstias infecciosas e epidêmicas $(20,9 \%)$ e, entre estes, a tuberculose respondia por quase $3 / 4$ dos mesmos. Os restantes deviam-se à febre tifoide, à malária e, em menor escala, à varíola. Em seguida, vinham as moléstias do aparelho circulatório (principalmente as afecções orgânicas do coração), do aparelho respiratório (com predomínio da pneumionia), do aparelho digestivo (preponderando as gastroenterite e enterite) e, em menor escala, outras que também ceifavam a vida de muitos adultos, homens e mulheres.

Como era de se esperar, a sazonalidade dos óbitos no Brás no decorrer do ano seguia tendência semelhante à observada na cidade de São Paulo. O final da primavera e os meses de verão, com temperaturas altas, concentravam a maior parte das mortes, sobretudo os meses de dezembro e janeiro. O clima quente contribuía para a proliferação de micróbios causadores de doenças do aparelho digestivo, a principal causa dos óbitos das crianças. No mês de fevereiro - por ser mais curto e de certa forma por seguir o pico dos óbitos dos meses que o precediam - e nos meses de inverno e início da primavera, o volume de mortes diminuía um pouco. No outono e

16 Nesta tabela não estão computados os dados para os anos de 1896 e 1897. 
inverno eram as enfermidades do aparelho respiratório e circulatório que faziam mais vítimas, levando a óbito aqueles mais debilitados (Cráfico 1).

Se as alterações de temperatura elevavam a incidência da tuberculose e de outras enfermidades do aparelho respiratório, como bronquite, broncopneumonia e pneumonia, a péssima qualidade da água, a precariedade da rede de esgoto, o acúmulo do lixo, e a proliferação de moscas e ratos disseminavam a malária e a febre tifoide na população local. A isso se somava a ausência de assistência à saúde, contribuindo para manter alta a morbidade e a mortalidade dos homens e mulheres, crianças e adultos do Brás.

No Brás, as melhorias quanto à saúde vieram muito lentamente com o passar do tempo. Obras de saneamento, vigilância e fiscalização sanitária, imunização, e controle de vetores contribuíram para o declínio da incidência de óbitos, principalmente os causados pela febre tifoide, pela malária e pela varíola. No caso da varíola, as campanhas de vacinação, de medidas de desinfecção e isolamento foram intensas no início do século XX; mesmo assim, ela voltou a ocorrer de forma epidêmica em 1912; já a febre tifoide reapareceu no Brás no início dos anos 1910 , período em que este local passava por uma deterioração muito grande (BASSANEZI, 2014).

Gráfico 1 -Sazonalidade dos óbitos. Brás 1895-1904.

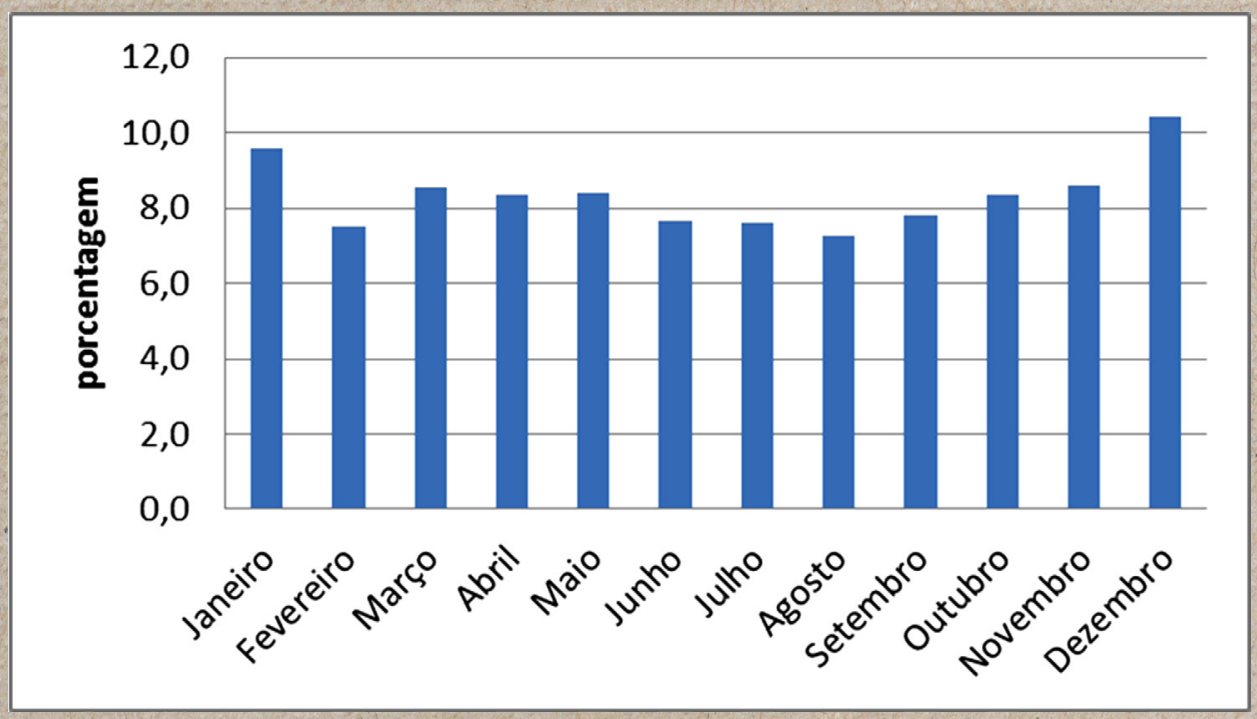

Fonte: Repartição de Estatistica e do Archivo do Estado de São Paulo (1896-1907).

A mortalidade infantil e os óbitos por tuberculose, por sua vez, mantiveram-se altos por mais tempo, dada à tênue ação oficial específica na redução de ambas. A alta mortalidade de crianças surtiu pouco impacto na adoção de políticas de saúde. As autoridades governamentais se empenharam mais em controlar as epidemias e doenças que pudessem prejudicar a política imigratória e a cafeicultura (RIBEIRO, 1991; TELAROLLI JR., 1996). 


\section{Considerações finais}

O olhar sobre as estatísticas de mortalidade da Hospedaria de Imigrantes e, sobretudo, as relativas ao bairro do Brás, nos dez anos que vão de 1895 a 1904, ainda que um tanto nebuloso, revela, de um lado, que a viagem fatigante, a aglomeração e a alimentação precária nos navios e nos trens que transportavam os imigrantes a São Paulo, juntamente com a aglomeração na própria Hospedaria de Imigrantes, debilitavam muito a saúde do imigrante, levando muitos a óbito. Por outro lado, a vivência de pobreza e miséria no bairro paulistano do Brás, enfrentada pelos imigrantes e seus descendentes, provocou uma mortalidade bastante elevada, semeIhante a que foi vivenciada na Europa um século antes, e maior que a enfrentada pela cidade de São Paulo como um todo e regiões cafeeiras do interior paulista, onde os imigrantes também eram muito numerosos. Em outros termos, o adensamento populacional provocado pelo movimento imigratório, pelas condições ambientais ruins, pela carência de assistência à saúde e de serviços médicos, e pela dieta precária fizeram com que os moradores desse bairro convivessem, naquele momento, com a alta morbidade e mortalidade, principalmente de crianças.

O Brás, um bairro que se urbanizava a passos largos, onde fábricas e oficinas eram instaladas e o comércio expandia-se, vivia, na época, um padrão de mortalidade que os demógrafos denominam de pré-transicional. Um padrão de mortalidade muito elevado, nada condizente a uma capital que tinha muito orgulho de seu desenvolvimento urbano, econômico e sociocultural, para o qual os muitos imigrantes deram sua saúde e suas vidas, mas do qual poucos puderam usufruir.

\section{Referências}

BASSANEZI, M. S. C. B. Nascimento, vida e morte na fazenda: alguns aspectos do cotidiano do imigrante italiano e de seus descendentes. In: DE BONI, L. A. (Org.). A presença italiana no.Brasil. Porto Alegre: Escola Superior de Teologia; Torino: Fondazione Giovanni Agnelli, 1990. p. 337-356.

Imigração e mortalidade na terra da garoa. São Paulo, final do século XIX e primeiras décadas do século XX, XIX. In: ENCONTRO NACIONAL DE ESTUDOS POPULACIONAIS, 19, 2014, São Pedro. Anais... Belo Horizonte: ABEP, 2014.

DIRECTORIA do Serviço Sanitária. Annuário Estatístico da Secção de Demographia, 1902. São Paulo: Typographia do Diário Official, 19.03. 


\section{História Econômicag Dossiê}

Annuário Estatístico da Secção de Demographia, 1903. São Paulo: Typographia do Diário Official, 1904. [AnnoX].

Annuário Estatístico da Seç̧ão de Demographia, 1904. São Paulo: Typographia do Diário Official, 1905. [AnnoXI].

LEVY, M. S. F. O papel da migração internacional na evolução da população brasileira (1872-1972). Revista de Saúde Pública, São Paulo, v. 8 [supl.], p. 49-90, 1974.

LIVI-BACCI, M. História de la población europea. Barcelona: Critica, 1999.

MORAES, G. S. Um ol har sobre a mortalidade em Campinas no final do século XIX: imigrantes e nativos. 2014. Dissertação (Mestrado em Demografia) - Universidade Estadual de Campinas, Campinas. 2014.

REPARTIÇÃO de Estatistica e do Archivo do Estado de São Paulo. Relatorio do Anno de 1895. São Paulo, Anno VIII da Republica [Apresentado em 30 de setembro de 1896 ao cidadão Dr. Antonio Dino da Costa Bueno, Secretario de Estado dos Negocios do Interior do Estado de São Paulo, pelo Dr. Antonió de Toledo Piza, Director], 1896.

Relatório do Anno de 1896. São Paulo, Anno X da República [Apresentado em 30 de setembro de 1897 ao cidadão Dr. José Pereira de Queiroz, Secretario de Estado dos Negocios do Interior, pelo Dr. Antonio de Toledo Piza, Director], 1897.

Relatório do Anno de 1897. São Paulo, Anno XI da República [Apresentado em 30 de setembro de 1898 ao cidadão Dr. João Baptista de Mello Peixoto, Secretario dos Negocios do Interior pelo Dr. Antonio de Toledo Piza, Director], 1898.

Relatório do Anno de 1898. São Paulo: Typographia do Diario Official, Anno XII da República [Apresentado em 20 de setembro de 1899 ao cidadão Dr. José Pereira de Queiroz, Secretario de Estado dos Negocios do Interior, pelo Dr. Antonio de Toledo Piza, Diretor], 1900.

Relatório do Anno de 1899. São Paulo: Typographia do Diario Official. Anno XIII da Republica [Apresentado em 12 de dezembro de 1900 ao cidadão Dr. Bento Pereira Bueno, Secretario de Estado dos Negocios do Interior, pelo Dr. Antonio de Toledo Piza, Director], 1900.

Relatório do Anno de 1900. São Paulo: Typographia do Diario Official. Anno XV da Republica [Apresentado em 13 de janeiro de 1902 ao cidadão Dr. Bento Pereira Bueno, Secretario de Estado dos Negocios do Interior, pelo Dr. Antonio de Toledo Piza, Director], 1903.

Annuario Estatistico de São Paulo (Brazil) 1901. São Paulo: Typographia do Diario Official, 1904.

Annuario Estatistico de São Paulo (Brazil) 1902. São Paulo: Typographia do Diario Official, 1905.

Annuario Estatistico de São Paulo (Brasil) 1903. São Paulo: Typ. Espindola, Siqueira \&Comp., 1905. 
. Annuario Estatistico de São Paulo (Brasil) 1904. São Paulo: Typographia do Diario Official, 1907. v. 1.

RIBEIRO, M. A. História sem fim... Um inventário da saúde pública, São Paulo, 1880-1930. 1991. Tese (Doutorado) - Universidade Estadual de Campinas, Campinas. 1991.

SECRETARIA dos Negocios da Agricultura, Commercio e Obras Públicas. Relatórios apresentados ao Presidente do Estado pelo Secretario da Agricultura. São Paulo: Typographia do Diario Official, 1898-1904.

Relatórios apresentados ao Presidente do Estado pelo Secretario da Agricultura. São Paulo: Typographia Brazil de Carlos Cerke, 1905.

SERVIÇO SANITÁRIO DO ESTADO DE SÃO PAULO (Estados Unidos do Brazil). Annuario Demographico: secção de estatística demógrafo-sanitaria. Anno XXIX, 1922. São Paulo: Typographia Brazil de Rothschild \& Cia, 1924. v.7.

TELAROLLI JR., R. Poder e saúde: as epidemias e a formação dos serviços de saúde em São Paulo. São Paulo: Unesp, 1996.

Epidemias no Brasil: uma abordagem biológica e social. 2.ed. atual. São Paulo: Moderna, 2003.

TRENTO, A. Do outro lado do Atlântico, um século de imigração italiaria no Brasil. São Paulo: Nobel; Instituto Italiano de Cultura de San Paolo; Instituto Cultural Ítalo Brasileiro, 1989. 